\title{
PRODUCTION OF A RALEIGH-TAYLOR INSTABILITY TARGET
}

Robert D. Day, Norman Elliott, Joyce Elliott, Veronica Gomez, Timothy Pierce, Douglas Hatch, Gerald Rivera, Elfino Armijo, Peter Gobby, Mike Brooks, Brian Hennike, Lawrence Rodriguez, Jake Bartos

Los Alamos National Laboratory

\section{INTRODUCTION}

Raleigh-Taylor (RT) instabilities occur when a low-density fluid attempts to accelerate a highdensity fluid. The instability manifests itself by forming bubbles of the low-density that percolate through the high-density fluid. Concurrently, spikes of the high-density fluid "jet" into the lowdensity fluid. This instability is seen in familiar occurrences such as the growth of icicles and the draining of sinks. If the interface between the two fluids remains perfectly smooth the instability will not occur; that is, it must be "seeded" by a wave-like perturbation. For the two cases mentioned above, a vibration can be sufficient to perform the "seeding".

The implosion of an Inertial Confinement Fusion (ICF) target often requires that a low-density fluid accelerate a high-density fluid. This leads to the possibility of developing RT instabilities that can produce a non-uniform implosion and drastically reduce the energy coming from the target. The "seed" for these instabilities comes from manufacturing defects such as surface finish or form errors. An illustration of manufacturing-induced RT instabilities is seen in figure 1[1] where the magnetic field acts as a low-density fluid that was imploding an aluminum cylinder. The high-density fluid in this case was the aluminum cylinder wall. The interface between the fluids was "seeded" by two different sine waves that were machined into the aluminum surface. The wavelength of the sine wave seen in the upper portion of the cylinder shown in figure 1 was $2 \mathrm{~mm}$. The wavelength of the lower sine wave was $0.75 \mathrm{~mm}$. Both sine waves had an amplitude of $25 \mu \mathrm{m}$. An examination of the data presented in figure 1 shows that as time increases the instabilities grow; however, the longer wavelength sine wave grows at a faster rate than the one with the shorter wavelength. These data, along with other data, have shown that there is both a wavelength and amplitude dependence on RT instability growth [2]. Since there will always be manufacturing defects in ICF targets and since RT instability growth is a rather complicated physical phenomena, a significant theoretical and experimental effort has been dedicated to understanding this phenomena.

\section{TARGET FOR OBSERVING RT INSTABILITY GROWTH LATE IN TIME}

A series of experiments have been performed at the Omega and Nova lasers to understand RT instability growth during the initial growth stages [2]. Since the laser used to illuminate the $x$-ray backlighters is only on for a time-duration of one nanosecond, observation of a fully developed instability can not be accomplished. Therefore, a target needed to be produced that would adequately simulate the geometry of a RT instability midway through its development. Drawings of the experimental package are shown in figure 2 . It was anticipated that the $30 \mu \mathrm{m}$ tall by 10 $\mu \mathrm{m}$ thick spikes and the $5 \mu \mathrm{m}$ thick base would be difficult to fabricate. It was decided to begin . two methods of production: machining and photolithography.

\section{MACHINED TARGET PACKAGE}

The machined targets were made according to the drawing in figure $2 \mathrm{~b}$. Approximately 10 targets of this style were needed for these experiments. It was decided to approximate the straight spikes by machining them on the rim a disc that was $70 \mathrm{~mm}$ in diameter. An aluminum disc was machined with the appropriate reference surfaces being diamond turned so that the tool location 


\section{DISCLAIMER}

This report was prepared as an account of work sponsored by an agency of the United States Government. Neither the United States Government nor any agency thereof, nor any of their employees, make any warranty, express or implied, or assumes any legal liability or responsibility for the accuracy, completeness, or usefulness of any information, apparatus, product, or process disclosed, or represents that its use would not infringe privately owned rights. Reference herein to any specific commercial product, process, or service by trade name, trademark, manufacturer, or otherwise does not necessarily constitute or imply its endorsement, recommendation, or favoring by the United States Government or any agency thereof. The views and opinions of authors expressed herein do not necessarily state or reflect those of the United States Government or any agency thereof. 


\section{DISCLAIMER}

Portions of this document may be illegible in electronic image products. Images are produced from the best available original document. 
could be determined to within a few micrometers. Copper was then deposited onto the rim of the disc. The disc was then remounted onto the diamond turning machine so the grooves could be machined into the copper.

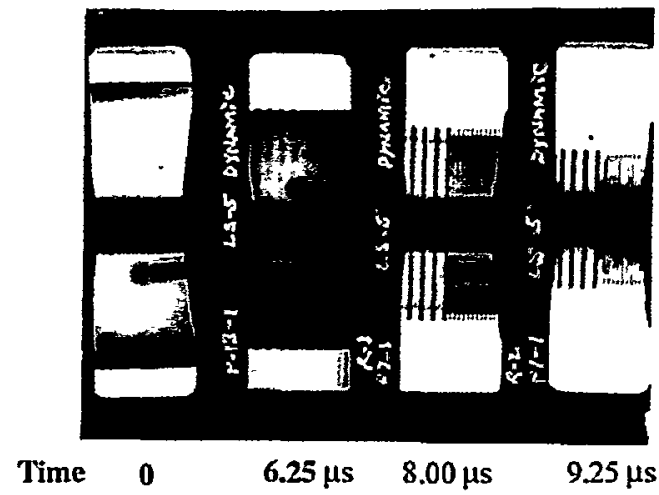

Figure 1-A series of radiographs taken perpendicular to the axis of an imploding aluminum cylinder showing the RT instability growth.

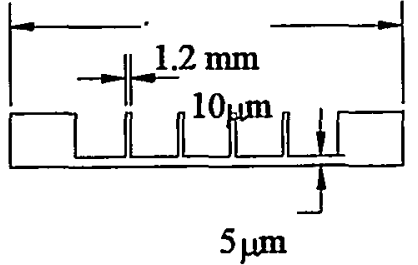

(a)

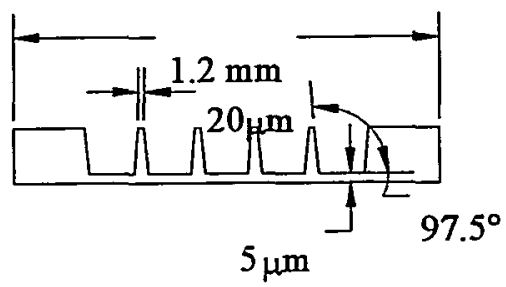

(b)

Figure 2 - Drawings of the two packages that were needed for the RT experiments.

The primary concern for the machined package was that the machining stresses would deform the thin spikes. After numerous discussions, it was decided to use a form-tool to produce the grooves. The design of the form-tool necessitated the $7.5^{\circ}$ angles that are shown on the drawing in figure $2 \mathrm{~b}$. Initially every other groove was machined, then these grooves were filled with wax to support the thin wall while the remaining grooves were being machined. After machining all of the grooves the wax was removed leaving a ring of copper material with the appropriate grooves machined into it. This process worked very well. All the critical dimensions were held to within $2 \mu \mathrm{m}$ of the desired amount. A cutaway view of the aluminum disc and the copper rim with the machined grooves is shown in figure 3.

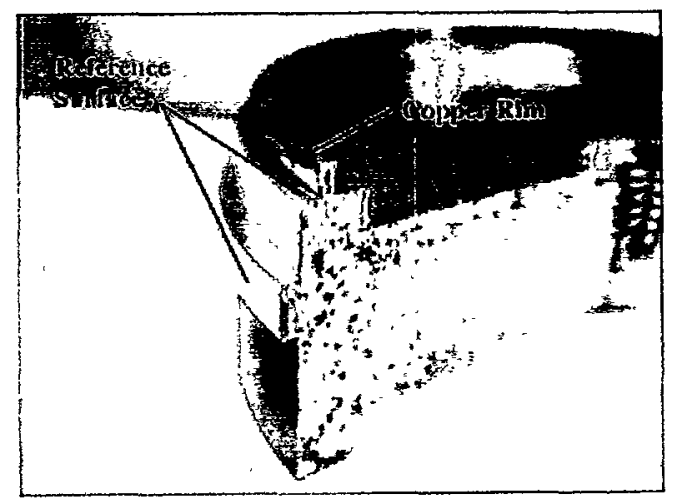

RECEIVED

DEC 132000

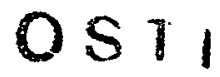


Figure 3 - A Photograph of the aluminum disc showing the copper rim with the machined grooves.

After machining the grooves, the parts needed to be cut to the proper width. This was performed with an Electron Discharge Machine to minimize machining stresses. There was considerable concern that the residual stresses from the machining operation would cause the packages to deform to such an extent that they could not be integrated into the entire target assembly. Therefore, it was decided to build the package supporting structure, as shown in figure 4, while the package was on the aluminum substrate. This structure would provide the necessary structural integrity to the package and make target assembly much easier. The package and its supporting structure would then be removed from the substrate. The supporting structure consisted of $150 \mu \mathrm{m}$-thick stand-offs that were glued to a $50 \mu \mathrm{m}$ thick gold washer. Each of the above steps required great care because of the delicate nature of the packages and the extremely small size of the components involved (particularly of the gold stand-offs). This assembly process, although tedious, worked very well. Figure 4 shows a package that has been EDMed to the correct width adjacent to an assembled package that is ready to be leached.

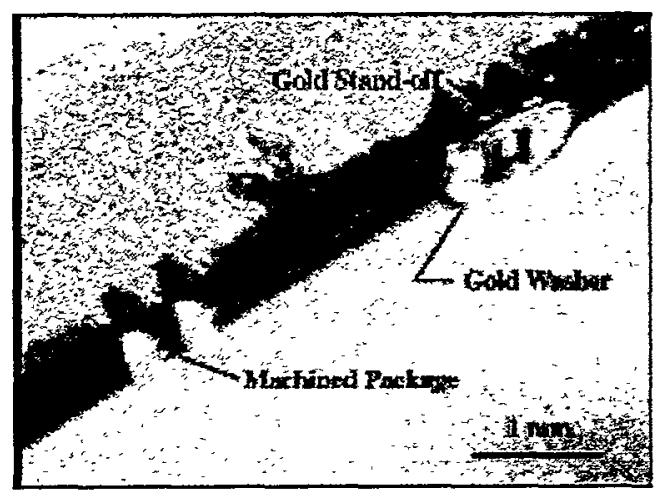

Figure 4 - Photograph of package EDMed to width adjacent to an assembled package ready to be leached

\section{PACKAGES PRODUCED USING ELECTRON DISCHARGE MACHINING (EDM)}

Fabrication problems with the packages produced by photolithography caused their delivery to be too late to be used in these experiments; therefore, they will not be discussed. A photograph of some of packages that eventually arrived is shown in figure 5. The photolithography fabrication problems caused a third fabrication approach to be used. This approach was to use the EDM process to make the entire package described in figure 2a. The same copper/aluminum substrate combination was used to produce these parts as was used for the machined packages. A Panasonic Micro EDM was used for these parts. It was decided to use this machine in a manner similar to a milling machine to produce these packages. This process is very labor intensive; however, the very tight schedule dictated that this approach should be attempted. This technique produced very good spikes; however the bottom web was estimated to be $15 \mu \mathrm{m}$. It is thought that an unknown amount of electrode wear was responsible for the thicker web. These packages did deliver very useful data [3].

\section{FINAL TARGET ASSEMBLY}

After the package assemblies were completed, they were mounted to the side of a sphere that had laser entrance holes machined into it that formed a tetrahedral geometry. The package, along with the backlighter and shield, needed to be mounted along a specific direction so that it would be illuminated properly. The accuracy of mounting was about $0.5^{\circ}$. A view of one of the final target assemblies is shown in figure 6. 


\section{CONCLUSIONS}

All of the fabrication methods described above worked well for producing the target packages desired. Great care and attention to detail was required at each step. Considerable forethought made the process proceed well even when unforeseen difficulties arose. The parts were produced in about two weeks from the making of the substrate to final target metrology. Photolithography is probably the optimum way to make this type of part if the schedule will allow it. The usefulness of having a Computer Numerically Controlled EDM for producing small quantities of these types of structures was also demonstrated by this project.

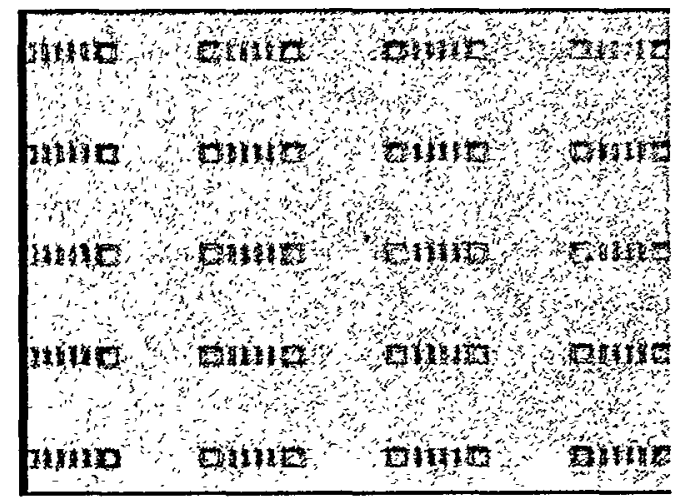

.Figure 5 - Packages made by photolithography process.

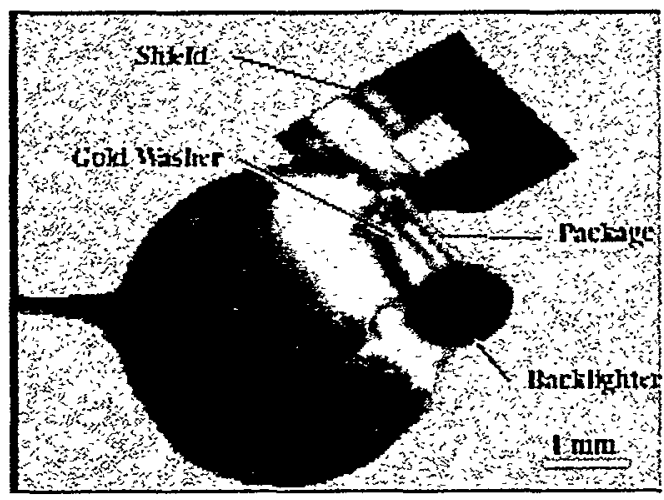

Figure 6-Photograph of final target assembly

Assembly, along with fabrication, can be very difficult. Forethought and the ability to handle very small parts facilitated being able to assemble these targets in very timely fashion.

In summary, the experimenters and theoreticians were very pleased with these targets. This set of experiments confirmed the theoretical calculations used to simulate RT instabilities.

\section{ACKNOWLEDGEMENTS}

We are grateful for the useful discussions with Bill May of Chardon Tool Company. He helped us think-through the machining process and his company produced the diamond tools. Dawn Skala of Sandia National Laboratory made sure the photolithography was performed very well and about as rapidly as was possible. A special thanks is also extended to Brian Hennike, Larry Rodriquez, and Bob Springer of Los Alamos National Laboratory for coating the aluminum substrates. This work was supported by the U.S. Department of Energy, office of Inertial Fusion, under the contract number W7405-ENG-36. This support is gratefully acknowledged.

\section{REFERENCES}

[1] Keinigs,R. K., Atchison, W. L., Faehl, R. J., Mclenithan, K. D., Trainor, R. J., "One-and Two-Dimensional Simulations of Liner Performance at Atlas Parameters," Proceedings VIII International Conference on Megagauss Magnetic Field Generation, Tallahassee, Florida, 1998.

[2] Hsing, W. W., Barnes, C. W., Beck, J. B., Hoffman, N. M., Galmiche, D., Richard, A., Edwards, J., Graham, P., Rothman, S., Thomas, B., "Raleigh-Taylor Instability Evolution in Ablatively Driven Cylindrical Implosions," Phys. Plasmas, 4, (5), May 1997.

[3] Schappert, G., Batha, S., Klare K., Hollowell, D., Mason, R, "Raleigh-Taylor Spike Evaporation," to be published. 